\title{
System of Performance Evaluation of Rice Paddy Production with Data Envelopment Analysis
}

\author{
Qori Halimatul Hidayah ${ }^{1, *}$, Mustafid ${ }^{2}$, and Kusworo Adi $^{3}$ \\ ${ }^{1}$ Magister Program of Information System, School of Postgraduate Studies, Diponegoro University, Semarang - Indonesia \\ ${ }^{2}$ Department of Statistics, Faculty of Science and Mathematics, Diponegoro University, Semarang - Indonesia \\ ${ }^{3}$ Department of Physics, Faculty of Science and Mathematics, Diponegoro University, Semarang - Indonesia
}

\begin{abstract}
Agriculture is one of the important factors in the development of the economy in Indonesia as an agricultural country because most of Indonesia's population has work in the field of agriculture or planting. Concepts and elements to understand and apply the performance calculations of evaluation of rice production using Data Envelopment Analysis. In this article convey and receive the evaluation of paddy production performance to know the value of efficiency and support in the process of paddy production in 2 planting seasons to find out the optimization of paddy production through performance evaluation Production to improve quality and be able to enrich the people. Input and output processes that have significance to improve the optimization of rice production and level to efficiency in rice production. This article will discuss the performance analysis of rice production and the results that will be given to know the efficiency in production and to help agricultural officers and farmers to produce an optimal and efficient product. Decision Making Unit (DMU) which has an efficiency value of fewer than 1 means inefficient whereas Decision Making Unit (DMU) whose value is 1 means efficient.
\end{abstract}

Keywords: Data Envelopment Analysis(DEA); Rice Paddy; Technical efficiency.

\section{Introduction}

Data Envelopment Analysis (DEA) is a wellknown mathematical procedure that uses linear programming (LP) techniques to assess the efficiency of the Decision Making Unit (DMUs) [1]. DEA has been widely applied to tackle decision analysis in various sectors [2]. DEA is usually used for production theory in economics, but it is also used for benchmarking in operations management to produce the efficient Decision Making Unit (DMU) [3].

DEA measures the efficiency of DMU based on inputs to DMU, which is often a resource used or consumed in operation, relative to the output of DMU, which may be a product or service offered by the system. Efficiency is a measure of managerial control that is useful for assessing how inputs and outputs act in relation to each other and with regard to the main key factors of rice production, such as irrigation, fertilization, spraying, and harvesting, Not only is it related to the process of requiring energy such as water, fertilizer and chemicals.

The basic feature of the DEA is the technical efficiency (TE) score of each DMU depending on the sample performance that is part of the DEA. TE is defined at the sample performance which is part DEA [4]. The TE is defined as the DMU capability to produce the maximum output given a set of inputs and technology levels, scoring is calculated by the ratio of the weighted output amount to the sum of the weighted inputs.

Agriculture one of the key sectors of the economy in Indonesia. Development in Indonesia is now a priority with the goal of improving social welfare. Performance evaluation of rice production is included in one of the agricultural products of various kinds of plants in the form of agricultural land, see the importance of the economy in Indonesia to make the evaluation of rice performance production into a report of agricultural products Much needed by developing countries to raise important roles in food safety.

In this research, researchers will implement performance system evaluation of rice production through the stages that have been compiled with analysis methods using Data Envelopment Analysis (DEA). This research is expected to be able to conduct evaluation studies on rice production, then produce that rice production has a different environmental impact and results from each season.

\section{Methods}

\subsection{Data Envelopment Analysis Model}

Data Envelopment Analysis (DEA) DEA as a linear programming-based (LP) technique to evaluate the relative efficiency of the decision-making unit, by

\footnotetext{
* Corresponding author: qoryhidayah@gmail.com
} 
comparing the DMU one with the other DMU utilizing the same resources for produce the same output [5]. Data Envelopment Analysis (DEA) is a non-parametric border estimation technique used extensively in many settings for measuring efficiency and marking unit decisionmaking (DMU)[6].

DEA is a mathematical programming technique based on linear programming that is used to evaluate the efficiency of a unit decision-making (working unit) responsible for using a number of inputs to acquire a targeted output. In this model, the delimiter function of each DMU has the same pattern, which differs only in the purpose function or the DMU function that will be measured. The DEA method was created as a tool for performance evaluation of activity in an entity unit (the organization) hereinafter called the Decision Making Unit (DMU). Simply put, these measurements are expressed by the ratio: output/input, which is a measurement of efficiency or productivity.

\subsubsection{Framework input and output DEA}

The DEA framework involving the retrieval of input and output data in the LCA involving the agricultural means of rice production can be seen in Figure 1 .

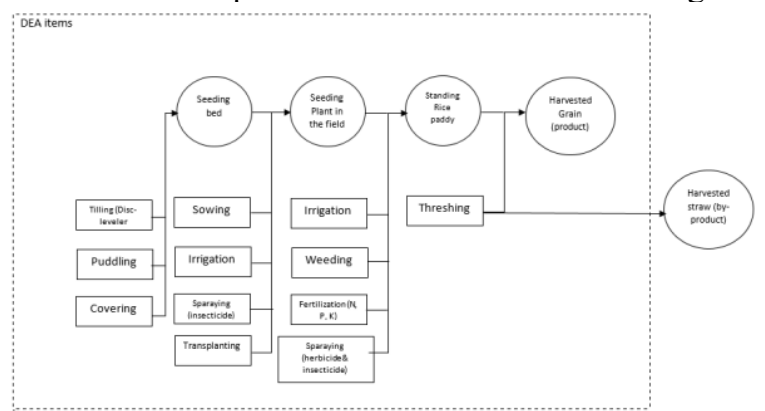

Fig. 1. DEA items for your DMU unit on each rice field [10].

In this study the use of the DEA method as already mentioned, the DMU Assessment Unit refers to each location.

\subsection{Technical Efficiency (TE) and Super Efficiency (SE)}

Technical Efficiency (TE) is defined as the ability of a DMU to produce the maximum output given a series of inputs and technology levels, and the scores are calculated with a ratio of weighted output amounts to the number of weighted inputs. Technical efficiency (TE) is defined as the capability of DMU to achieve maximum output of the given inputs, while allocation efficiency is defined as the success of DMU in selecting inputs in optimum proportion with respect to the price [7]. Efficiency has a sense of comparison between output and input [8]. The basic feature of DEA is that the technical efficiency score (TE) of the sample is part of the DEA [4]. Technical efficiency is seen at the input or output level. Being technically efficient means minimizing inputs at a given output level, or maximizing output at a certain input level [9].
The Efficiency (TE) technique is essentially the same as the DMU size that is valued for its performance relative to other DMU in the sample and can be expressed in eq (1) according to [10].

$$
\begin{aligned}
& T E=\frac{\text { Weighted sum of outputs }}{\text { Weight sum of inputs }}
\end{aligned}
$$

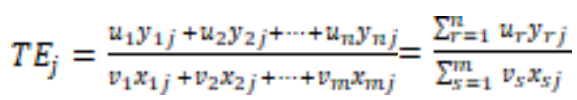

$$
\begin{aligned}
& \text { Maximize } \theta_{j}=\frac{\sum_{y=1}^{n} u_{y} y_{r j}}{\sum_{g=1}^{m} v_{s} x_{s j}}
\end{aligned}
$$

$\mathrm{u}_{\mathrm{r}}$ is a weighting of $\mathrm{y}_{\mathrm{r}} \cdot \mathrm{v}_{\mathrm{s}}$ output as the weight of an $\mathrm{X}_{\mathrm{S}}$ input. $r$ and $s$ represent specific outputs and inputs. TEj and $\theta \mathbf{j}=$ technical efficiencies from DMU are considered, in this study of DMU is the number of rural areas that became the locations considered in the study. Note the number of inputs $(\mathrm{s}=1,2, . ., \mathrm{S})$, increase the number of outputs $(\mathrm{R}=1,2, . ., \mathrm{R})$ and $\mathrm{J}$ represent DMU to-j $(j=1,2, . ., J)$.

If there is a value of DMU that wants to compare its efficiency level then a linear DEA the fraction can be the right choice in determining the value of efficiency levels as in the formula (4).

$$
\text { Maximize } \theta_{j}=\frac{\sum_{y=1}^{n} u_{y} y_{r j}}{\sum_{g=1}^{m} v_{g} x_{s j}}
$$

Subject to

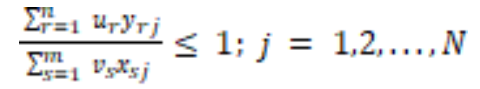

$$
\begin{aligned}
& \text { u rj ,v sj } \geq 0 ; m=1,2, \ldots, N ; n=1,2, \ldots, N
\end{aligned}
$$

$\theta_{\mathrm{j}}$ As the $\mathrm{j}$ efficiency of the DMU. $\mathrm{y}_{\mathrm{rj}}$ represents the-r output for DMU to-j. $U_{\mathrm{rj}}$ is the output weight. $\mathrm{x}_{\mathrm{sj}}$ is the to-s input for DMU to-j and $\mathrm{x}_{\mathrm{sj}}$ notation for input weights.

The DEA models that were first introduced by Charnes et al (1978) Linear Programming (LP) formulas were written as in the formula (5) according to [11].

$$
\text { Maximize } \theta=\sum_{y=1}^{n} u_{r} y_{r o}
$$

Subject to

$$
\begin{aligned}
& \sum_{s=1}^{\mathrm{m}} \mathrm{v}_{s} x_{s o}=1 \\
& \sum_{y=1}^{\mathrm{n}} u_{r} y_{r i} \leq \sum_{g=1}^{\mathrm{m}} \mathrm{v}_{g} x_{s i} ; n=1,2 \ldots \ldots \\
& \mathrm{u}_{r}, \mathrm{v}_{s} \geq 0 ; m=1,2, \ldots, N ; n=1,2, \ldots, N
\end{aligned}
$$


$\mathrm{x}_{\mathrm{sj}}$ is the number of inputs to-r from DMU to-m and $\mathrm{y}_{\mathrm{rj}}$ is the number of outputs to-m. DMU whose efficiency value is less than 1 means inefficient, while DMU whose efficient value equals 1 means efficient.

In fact, in the second (envelopment) of the problem, this research is easier to solve the above equation due to fewer constraints. Mathematically, the double linear problem can be written in the vectors, the notation in the formula (6).

$$
\text { Manimize } \theta
$$

Subject to

$$
\mathrm{Y} \lambda \geq y_{0}
$$

$$
X \lambda-\theta x_{0} \leq 0
$$$$
\lambda \geq 0
$$

$\mathrm{x}_{0}, \mathrm{y}_{0}=\mathrm{X}_{\mathrm{j}}, \mathrm{Y}_{\mathrm{j}}$ is the input and output of DMU for evaluation, and the total number of DMU is considered in the DEA analysis. $\lambda$ is $n \times 1$ vector weight. If $\theta=1$, means that DMU will be considered efficient whereas, 0 $\leq \theta<1$, it represents that DMU is inefficient.

Super Efficiency (SE) is the approach to achieving this goal. In the SE method, DMU that is being evaluated is not included in the reference set so that the efficient DMU can have an efficiency score greater than or equal to 1 .

$$
\text { Manimize } \theta
$$

Subject to

$$
\begin{aligned}
& \sum_{j=1}^{n} \lambda_{i} Y_{r j} \geq y_{r 0} \\
& \sum_{j=1}^{n} \lambda_{j} Y_{i j} \leq \theta_{0} x_{i 0} \\
& \sum_{j=1}^{n} \lambda_{j} \geq 1 \\
& \lambda_{i j} \geq 0
\end{aligned}
$$

$\theta_{0}$ Super Efficiency (SE) is DMU efficient.

\section{Implementation}

Model used in the development of the system is waterfall model, this model performs systematically and sequentially approach in making software ranging from level of system needs to the needs of analysis stage, system design, implementation, testing and operation, and maintenance. The materials used in this study are extensive data on paddy fields, fertilizer data, planting data, harvest data, and crop failure data during the planting season. System Framework performance evaluation of rice production is three stages of input process output.

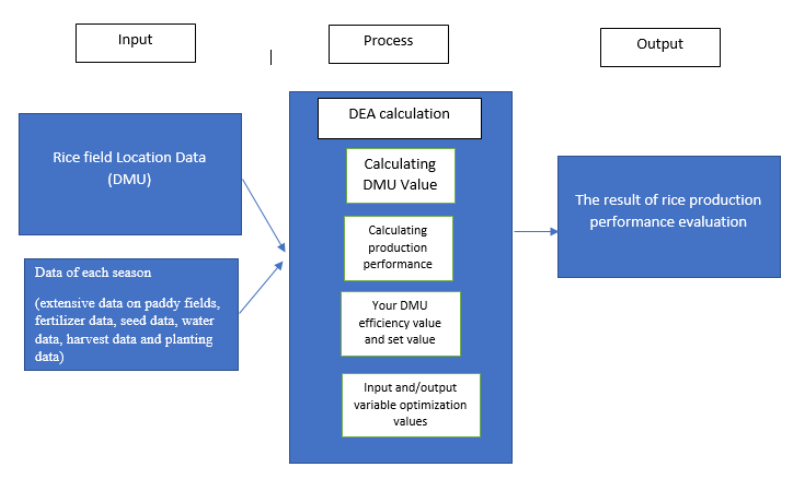

Fig. 2. Analysis of process flow

The first stage is the input or process of data entry into the system, the data entered is the location data of the rice fields namely DMU data and the data of each season consisting of extensive data on paddy fields, fertilizer data, seed data, water data, harvest data, and data planting. The second stage is the data processing process using DEA by calculating the location or village value as DMU and the set value, then the efficiency value of the location or village called DMU efficient or inefficient the latter counting the changes in the input variables and output. The third stage is the output or output of data that has been processed and displayed into the monitored system resulting in the evaluation of the performance of rice production, the location of any village that produces maximum rice harvest, the location of any village that Experienced a minimum harvest and factors affecting rice harvest.

\section{Result and Discussion}

Based on the data there is a result of calculation using DEA. DMU whose efficiency value is less than 1 means inefficient, while DMU whose efficient value equals 1 means efficient. The example of data taken on this paper states inefficient because the technical value of the efficiency contained shown in Table 1 is less than 1 .

The Data available states that Paddy harvest is very dependent on the needs of water, so that water becomes high weight in the production process, in addition to rice plant water also relies heavily on fertilizer for the growth process so that from various Kinds of fertilizers that have different weights according to their function, from each data needs of rice production is assessed from the stipulated weights then using the DEA analysis in the calculation of the results of the weights that are already available. The data provided by flatten is a unit of $\mathrm{kg}$ and then calculated efficiency techniques to know which areas are experiencing the rise and fall of paddy production efficiency, from the processed data will be visible areas of loss Largest and largest production in one season and any factors that influence it.

In the Planting Season 1 (PS1) has no efficiency of paddy production because the production facilities are more used but not in accordance with the results harvested and in the Planting Season 2 (PS2) is experiencing inefficient because of the crop failure 
occurred From several factors namely the wind is too tight, fertilizer that use too much, the number of pests that attack and or the amount of water volume too large or slightly

Table 1. Data Result

\begin{tabular}{|c|c|c|c|}
\hline DMU & & PS1 & PS2 \\
\hline \multirow{8}{*}{ Input } & Land (ha) & 64 & 92 \\
\hline & $\begin{array}{l}\text { Urea Fertilizer } \\
(\mathrm{kg})\end{array}$ & 12800 & 1840 \\
\hline & $\begin{array}{c}\text { SP-36 Fertilizer } \\
(\mathrm{kg})\end{array}$ & 6400 & 9600 \\
\hline & $\begin{array}{l}\text { ZA Fertilizer } \\
(\mathrm{kg})\end{array}$ & 6400 & 9400 \\
\hline & $\begin{array}{l}\text { NPK Fertilizer } \\
(\mathrm{kg})\end{array}$ & 19200 & 27200 \\
\hline & $\begin{array}{c}\text { Organic } \\
\text { Fertilizer }(\mathrm{kg})\end{array}$ & 32000 & 46000 \\
\hline & Water Data $(\mathrm{l} / \mathrm{dt})$ & 2400 & 4900 \\
\hline & Seed Data (kg) & 83 & 128 \\
\hline \multirow[b]{2}{*}{ Output } & Harvest (ton) & 30 & 50 \\
\hline & $\begin{array}{c}\text { Crop Failure } \\
\text { (ton) }\end{array}$ & - & 10 \\
\hline TE & & 0,547 & 0,715 \\
\hline
\end{tabular}

The efficiency techniques of data samples in table 1 The data is processed in the system and will be known for what the value of cropping technique Planting Season 1 (PS1) in December, January, February and March then planting Season 2 (PS2) in April, May, June, and July. The remainder of the next month in August, September, October and November is called Gadu season or month which depends on the availability of water in the process of rice planting, if the water is adequate to plant rice then the planting process, if water shortage Then implanted plants that can survive with a small amount of water.

Data that is very affecting rice production is the amount of water and fertilizer. Based on 14 village data producing rice states there is a village whose value is efficient and inefficient in production on which is calculated using Data Envelopment Analysis.

\section{Conclusion}

This research analysis of the efficiency of the 14 villages that have 2 planting season period namely planting Season 1 in December, January, February, and March then the planting season 2 in April, May, June and July. Results of the DEA analysis calculation stated that in the planting Season 1 and 2 environmental impacts are very influential so that the production gained in the planting period 1 is still not efficient, while in the planting season 2 suffered a loss that is failed to harvest so not yet streamlined. Based on the data that has been obtained states that the optimization of inputs and/output with DEA shows that environmental conditions indicate that it has a large impact on rice production. From the results of the available data can be calculated that the data each season has a difference in results for each rice production performance in each region.

\section{References}

1. A. Mohammadi, S. Rafiee, A. Jafari, A. Keyhani, T. Dalgaard, M. T. Knudsen, Thu Lan T. Nguyen, R. Borek, and J. E. Hermansen, J.E. Journal of Cleaner Production, 106, 532 (2015)

2. D. Liu, Y. Kang, Chinese Control and Decision Conference (CCDC, 2015)

3. J. Zhu, W.D. Cooka, K. Tone, Data Envelopment Analysis: Prior to Choosing a Model, Omega, 44 (2014)

4. P. Martinez and S. Silveira, Renew Sustain, Energy Rev, 16 (2012)

5. P.F. Tsai and C.M. Molinero, European Journal of Operational Research, 141 (2002)

6. N. Adler, L. Friedman, Z. Sinuany-Stern, European Journal of Operational Research, 140 (2002)

7. N.M. Malana, H.M. Malano, Irrig Drain, 55 (2006)

8. I. Syamsu, Efisiensi, Sistem dan Prosedur Kerja (Bumi Aksara, jakarta, 2007)

9. K. Vincova, Using DEA Models To Measure Efficiency, BIATEC, 13 (2005)

10. A. Mohammadi, S.H. Rafiee, S.S. Mohtasebi, S.H. Mousavi-Avval, H. Rafiee, Renew Energy, 36 (2005)

11. S.H. Mousavi-Avval, A. Mohammadi, S. Rafiee, A. Tabatabaeefar, Journal of Cleaner Production, 27 (2012) 